\title{
ASHIS NANDY E AS VICISSITUDES DO SELF: CRÍTICA, SUBJETIVIDADE E CIVILIZAÇÃO INDIANA
}

José Maurício Domingues

\section{Introdução}

A Índia é um país de enorme criatividade cultural, historicamente com muitas inovações nos planos religioso e filosófico, ao que se acrescentou, desde seu contato inicial com a modernidade, o desenvolvimento de ciências humanas e sociais de alta qualidade. Ashis Nandy se insere nesse contexto como um dos grandes nomes de sua psicologia, com uma produção voltada para temas políticos e sociológicos. Sua obra, de cunho eminentemente ensaístico, é muito rica e ao mesmo tempo polêmica de forma radical, sobretudo na medida em que se afasta de perspectivas mais explicitamente modernas. Por ser bastante complexa e também longa, tratarei aqui de selecionar alguns eixos fundamentais que me parecem, de um lado, proporcionar uma visão geral de sua perspectiva e, de outro, oferecer instrumentos particularmente interessantes às ciências sociais contemporâneas. Primeiramente, vou debruçar-me sobre sua concepção de crítica, tradição e utopia, civilização e cultura. Em seguida, vasculharei a teoria do self e suas múltiplas faces, talvez sua contribuição mais original a nossas disciplinas, tratando de vários temas da cultura indiana. Enfim, deter-me-ei em questões mais específicas, mas explosivas, que dizem respeito ao debate sobre a modernização e o desenvolvimento, o Estado e o nacionalismo, secularismo e secularização na Índia hoje. Aí encontraremos o que me parecem ser os limites do pensamento de Nandy. Antes disso, cumpre apresentar um breve retrato geral do autor e de sua obra.

Criado em Calcutá na segunda metade do século XX, ou seja, testemunha desde jovem da trajetória da Índia independente, Nandy se formou e pós-graduou em psicologia, com forte ênfase em psicanálise. Trabalhou clinicamente até optar em definitivo por uma carreira de pesquisador, vinculado ao Centro para o Estudo das Sociedades em Desenvolvimento 
(CSDS), em Nova Déli. Os temas da criatividade na ciência e na literatura, assim como a articulação entre personalidade e sociedade, foram seus focos iniciais, embora desde sempre trabalhasse com uma "psicologia política" e as questões da sociedade indiana estivessem no centro de suas preocupações, em parte sob a mediação da figura do Mahatma Gandhi (1869-1948), bem como de Rabindranath Tagore (1861-1941), o grande literato e compositor da primeira metade do século XX indiano. ${ }^{1}$ Cada vez mais busca um resgate da tradição indiana, a partir do que seriam, sobretudo, suas vertentes populares, indo contra noções de secularismo e desenvolvimento, criticando fortemente o Estado e os intelectuais mais explicitamente modernos. Na verdade, a meu ver um excesso de estridência vem prejudicando a elaboração de suas ideias e mais recentemente há de fato certa perda de substância em suas concepções, não obstante a importância de sua obra de modo geral.

Para alguns, Nandy teria uma perspectiva brâmane, pois as tradições que defende são contrárias a uma perspectiva progressista radical e não a incluem, sendo ele ambiguamente antifeminista ${ }^{2}$ e cúmplice em certa medida do chauvinismo do nacionalismo hindu por suas posições antissecularização, assim como da crítica pró-mercado e anti-Estado do neoliberalismo (Desai 2002:78-90). Ele concentraria seu "tradicionalismo crítico" — que adiante analisarei - somente em ataques à ciência, poupando as tradições, sem entender que o problema da Índia é a falta de "Esclarecimento" (Nanda 2004:42-3, 168-9, 211). Nandy seria incapaz de ver, ao opor-se ao secularismo, a importância de uma esfera pública democrática para a Índia (Nag 2002:535-6). Mais profunda é a crítica de Baber (2006:34-41), segundo a qual não apenas Nandy teria tido um pé na teoria da modernização, como suas dicotomias teriam sobrevivido, ainda que transformadas, em seus textos, visão com a qual concordam até mesmo alguns dos que o têm em alta conta (Paranjape 2000:241).

A visão de Vanaik (1997:165-77) é mais nuançada. Para ele, Nandy, conquanto não consiga perceber que a Índia está há muito condenada à modernidade, teria uma compreensão relativamente profunda desta, mas na verdade não da tradição, sustentando noções frouxas de secularismo e secularização, com muitas ambiguidades em suas formulações conceituais. Ademais, diferentemente de T. N. Madan, Nandy nada teria de brâmane em sua perspectiva, havendo de fato - ao contrário deste, também crítico das ideias de secularização - corajosamente apoiado em Mandal Report, uma exaltação à ampliação da ação afirmativa de modo a avançar a posição das castas desfavorecidas no país (Vanaik 1997:215, nota 52). Acentuando a originalidade de Nandy e o fato de não ser um "atavista", Chakrabarty (2000) observa que sua crítica à modernidade é fundamentalmente moderna, pois 
se configura como "decisionista" ao supor que se poderia fazer uma ruptura baseada na vontade, ao recuperar a tradição como uma "autoinvenção heroica" - o que é falso. Nandy tem, por outro lado, um grupo de admiradores extenso e até bastante acrítico, que tende a acentuar sua originalidade e genialidade (Lal 2000; Sardar 2000; Buell 2000; Dirlik 2000) e que por vezes reage com irritação a críticas a ele (Lal 2001). Não há, contudo, uma exploração sistemática de seus escritos em nenhum lugar (exceção parcial, no que concerne à psicologia "pós-colonial", é Greedharry 2008, capítulo 2), embora direta ou indiretamente sua obra sirva como ponto de referência para muitos dos debates na academia indiana hoje. ${ }^{3}$

Ao concluir, terei a oportunidade de revisitar essas discussões, em particular a relação entre modernidade e tradição na obra de Nandy. Exploremos agora seus eixos principais. Além de nos permitir penetrar suas ideias, isso nos possibilitará a identificação de alguns temas cruciais para a compreensão da Índia em termos históricos e contemporaneamente.

\section{Crítica e tradição, modernidade e utopia}

A noção de crítica imanente, a que estamos mais acostumados, parte da própria modernidade e da cobrança em relação a suas limitações no plano da realização de seu próprio horizonte normativo (Domingues 2002:35-ss). É a ela que Nandy se refere ao dizer que a modernidade não pode viver sem seu oposto - o modernismo crítico, uma crítica interna à modernidade. Há críticas que vêm, contudo, de fora da modernidade, rejeitando os valores da Ilustração, consistindo em uma crítica externa, na qual ele inclui, curiosamente, autores como Carlyle, Emerson, Thoreau, Ruskin e Tolstói. A perspectiva de Nandy se aproxima desta segunda, ainda que ele oscile um pouco no que concerne a sua unilateralidade ou capacidade de síntese - e que seja um tanto estranho listar autores ocidentais ou quase, que dificilmente em outro contexto seriam vistos como alheios à modernidade, como exemplos de outra perspectiva. Para Nandy, Gandhi seria, não obstante, o crítico "mais consistente e selvagem" da modernidade, objeto assim de sua admiração, embora recuse se considerar um gandhiano. Gandhi defendia a tradição das vilas indianas, dinâmica, e estava disposto a criticar fortemente a tradição, como ele crê haver sido o caso nas discussões sobre as castas, conquanto o próprio Gandhi vivesse dentro da tradição, incorporando elementos modernos sem embaraço. Neste e em outros casos, isto implica o "tradicionalismo crítico" (Nandy 1992a:121-5; 1992b:153; 1987:114-6; 2008a), pois, como disse mais recentemente, do mesmo modo como a modernidade tem 
sua própria tradição, outras tradições podem funcionar como uma forma de "negação", tal qual elaborada por Marcuse (Nandy 2006:59, 64).

Para ser crítico, porém, o tradicionalismo deve ter sua própria teoria da opressão e uma percepção das fontes do mal nos tempos modernos. Se apenas teorias nativas podem oferecer conceitos para tratar de opressões nativas, nenhuma delas pode ser levada a sério se não os incluir, além de possuir uma teoria do próprio ocidente. O espírito se faz assim presente nas ideias indianas, bem como a noção de um "eu" (self) tanto interno quanto socialmente construído. As teorias modernas, em contrapartida, podem ou não ajudar os oprimidos (embora decerto auxiliem os teóricos) (Nandy 1987:117-21). Afinal, toda cultura tem suas patologias e um lado negro (Nandy 1995e:49). Se isto é verdadeiro genericamente, em termos de sua ciência, em particular, ele demandou uma psicologia aberta à diversidade "étnica", necessariamente política. A teoria crítica deveria ser então buscada sem deixar de lado a pluralidade cultural e normativa (Nandy 2007a:120-6). Assim se poderia escapar do etnocentrismo da psicanálise e do marxismo, que eram críticas internas do ocidente (Nandy 1995b:81), mas, sobretudo, atingir uma linguagem crítica que não fosse alheia à maioria da população indiana, que ganhava poder com a abertura democrática (Nandy 1995f: vii). Ademais, Nandy (2002c:208-9) identifica uma domesticação da teoria crítica ocidental e sugere que as "culturas derrotadas dos trópicos" podem oferecer-lhe uma contribuição positiva, renovadora. Ele se distancia, com isso, da anteriormente forte influência da Escola de Frankfurt (Nandy 2007c:57; 2006:16, 18-20). Seu tradicionalismo crítico aceitaria a ciência, recusando, porém, uma preocupação excessiva - coordenada pelo mecanismo de defesa conhecido como "isolamento" — com a objetividade, em detrimento ou mesmo cancelamento dos afetos e da especulação filosófica (Nandy 1992c:125). Mas uma coisa acaba sendo clara, não obstante o desenvolvimento por vezes oscilante da argumentação e a admissão de ser dificilmente encontrável a disjunção entre modernidade e tradição em uma forma pura: " [...] a escolha é entre o modernismo crítico e o tradicionalismo crítico. Trata-se de uma escolha entre dois quadros de referência e duas visões de mundo" (Nandy 1987:116).

A crítica de Nandy à modernidade está vinculada diretamente a uma visão de futuro, à utopia, tema difícil no violentíssimo século XX. Reconhecer isto implica que qualquer uma delas deve estar baseada em uma percepção da violência que as diversas "fés" podem desencadear. As utopias devem ser postas em juízo, portanto, tendo em mente sua capacidade de autoavaliação e responsabilidade por seus "rebentos cerebrais legítimos e ilegítimos", sem mencionar o fato de que sociedades imperfeitas produzem 
remédios imperfeitos. Os utopistas têm de estar dispostos a engajar-se em um diálogo; isso não pode funcionar se os "heréticos" e os de fora forem tratados como inferiores. Em qualquer sociedade, inclusive a indiana, é preciso abraçar elementos da cultura e recusar muitos de seus outros traços (Nandy 1992d:6-9, 22).

Em outro ensaio, o tema é tratado ainda mais profundamente, em um diálogo velado com Max Weber, jamais citado nesse contexto, cujas temáticas da salvação e da liberdade - esta última implícita, mas oculta, na obra do autor alemão, em função de sua ênfase na racionalização (Domingues 2002:75-7) — influenciam muito o tom do artigo. Ao discutir uma "perspectiva intercivilizacional quanto à opressão", com um complemento menos articulado sobre a "psicologia da sobrevivência e da salvação", Nandy argumenta que o teórico do Terceiro Mundo teria de converter-se na "representação coletiva" das "vítimas do sofrimento criado pelo homem em qualquer lugar do mundo e em qualquer tempo passado". Deveria reconhecer também as forças externas de opressão, tratando-as como internas, e incluir os "eus (selves) marginalizados" do Primeiro Mundo e do Segundo como "aliados civilizacionais" na luta contra o "sofrimento institucionalizado". Ademais, todas as civilizações compartilham alguns valores básicos, derivados das "verdades eternas da natureza humana": a diferença reside na gestalt (termo que não define) e no peso que recebem, dividindo-se entre "dominantes" e "recessivos". Toda a história da civilização seria uma tentativa de alterar ou expandir sua "percepção da exploração e da opressão", ainda que sociedades imperfeitas produzam remédios imperfeitos - como Marx e Freud perceberam, pois viam que não podíamos simplesmente nos desfazer do passado, conquanto fossem demasiadamente otimistas - até porque as sociedades criam "defesas internas poderosas" contra a percepção do sofrimento e os oprimidos podem, como observou Erich Fromm, lograr ganhos psicológicos secundários com sua situação. A liberdade interna do eu deve sustentar a liberdade externa para que esta possa medrar e a humilhação que se põe nas relações entre senhor e escravo possa ser ultrapassada (Nandy 1992c:21-2; 2007f).

Especialmente por compartilhar os quadros disciplinares da psicologia política, assim como da luta anticolonial, é importante para Nandy distanciarse de Franz Fanon, figura ícone nessas coordenadas. Segundo ele, a violência não é solução de modo algum, nem terapeuticamente para o oprimido: se Fanon tivesse um pouco mais de confiança em sua cultura, não necessitaria dela para exorcizar a opressão e a violência internalizada, o que, além disso, vincularia ainda mais o oprimido ao opressor, por meio de sua socialização quanto aos valores deste e da abertura das pulsões agressivas de maneira 
livre. Como Gandhi havia percebido, calcado tanto no monismo tradicional indiano e em sua visão de renúncia quanto nos valores cristãos originais, era preciso libertar também o opressor. Somente os fracos e humildes podem ser a ponta de lança desse processo, pois possuem a verdadeira inocência de que falava Rollo May, isenta da satisfação das gratificações secundárias dos "pseudoinocentes" que absorvem os valores da opressão. Afinal, ele via a liberdade como indivisível, com ambos, opressores e oprimidos, capturados nas teias da opressão e carecendo libertar-se (Nandy 1992c:34-5; 1988:63). Não se trata de projetar uma consciência futura ou de cultivar a culpa do Primeiro Mundo, mas sim de agregar ou sintetizar visões do futuro que autenticamente derivem de cada "civilização", reconhecendo, ao mesmo tempo, a experiência de sofrimento compartilhado. Afinal, os valores básicos são comuns e transcendem o particularismo, que não serve como cura para o etnocentrismo. O relativismo cultural só é válido se aceita "o universalismo de alguns valores centrais da humanidade". A visão autêntica de cada civilização requer, assim, alianças com forças exteriores, na busca dos elementos recessivos internos e com a disposição de se envolver com o outro em sua busca própria (Nandy 1992c:54-5). Eis aí o caminho da "salvação", da liberdade. Como veremos adiante, há muito aqui relacionado a Gandhi e à cultura índica, suas metas se pondo universalmente, contudo.

Ainda com referência a Gandhi, pode-se perceber em parte o que na prática tal tradicionalismo crítico e visão de futuro significariam, pois Gandhi introduziu mudanças radicais, embora não pensasse em si mesmo como um reformador e vivesse a tradição. Legitimou uma ética coletiva que alterou os conceitos de salvação individual, de responsabilidade e ação voltadas para o valor da autopercepção; deslocou o conceito de autoconhecimento meramente privado; e mudou a perspectiva da participação política, mobilizando as massas, em oposição à visão indiana tradicional segundo a qual as autoridades políticas não eram centrais para a vida social (Nandy 1990d:75). Em outras palavras, deixando de lado um ascetismo dirigido para fora do mundo, característica das principais correntes religiosas hindus, Gandhi relocaliza a transcendência, com a liberdade devendo ser buscada neste mundo, ponto com o qual evidentemente simpatiza Nandy, conquanto mesmo nesse passo, como veremos adiante, marque diferenças claras em relação à cultura ocidental dominante.

Em suma, podem-se depreender da análise dos textos de Nandy duas visões do que seria a relação entre a teoria crítica ocidental, tipicamente moderna, e a articulada a partir de outras perspectivas civilizacionais, o que evidentemente apresenta consequências quanto ao futuro. A primeira implicaria uma complementação da teoria crítica, ou sua transformação 
parcial. Esta seria uma versão fraca da perspectiva crítica alternativa. A segunda, mais forte, aponta outra direção, em que uma crítica externa teria total autonomia e se encontraria em pé de igualdade com aquela ou mesmo desfrutaria de certa superioridade - fora da modernidade, oriunda de outros elementos, e em oposição a ela em grande medida, retomando visão bastante tributária do próprio Gandhi. A primeira permite uma síntese futura mais clara, a segunda sublinha uma separação. O que permitia que essa tensão interna ao argumento de Nandy fosse parcialmente resolvida era o fato de ele acentuar a universalidade dos valores básicos de todas as civilizações. Mais recentemente, todavia, ele vem assumindo uma posição mais unilateral, com afirmações sobre a capacidade dos seres humanos de produzirem "novos instrumentos de violência e opressão" a partir de ideias emancipatórias, algo tornado mais agudo pela modernidade, o que demandaria sistemas alternativos de conhecimento, sendo que civilizações como a Índia e a China localizam suas utopias no passado e não no futuro, ao contrário do que se passa com a Ilustração (Nandy 2007g:IX-XV). ${ }^{4}$

Mas o que seria uma civilização? Este é na verdade um dos conceitos mais usuais - ao menos até recentemente - e mais vagos na obra de Nandy. Elas são plurais, como as tradições, e algumas capazes de acomodar a modernidade, emprestando antigos significados a novas experiências (Nandy 1990c:47; 1990d:76; 1992a). Em geral ele prefere falar das grandes civilizações, como sobretudo a indiana, mas pode reconhecer o caráter "insuficientemente global" da civilização hoje, que a faz ao mesmo tempo paroquial em seu ocidentalismo e um ponto de referência para outras civilizações (Nandy 2007b:173). Talvez por sua definição vaga ele tenha reduzido o uso do conceito ao longo do tempo, sem deixar de reafirmar que, ainda que a distinção tenha algo de forçado, as civilizações são sempre plurais, ao contrário de culturas, unitárias, e podendo acomodar construções inautênticas sem sucumbir à inautenticidade em si, ao contrário das culturas (Nandy 2000b:44-7, 84). ${ }^{5}$ Vale notar, no entanto, que ele acentua muitas vezes uma dicotomia entre modernidade e tradição (Nandy 1987:114; 2000b:64), ou seja, entre civilizações, embora esteja ciente de que elas não se encontram tão contrapostas na Índia e confesse, em entrevista, que tal fato se deve antes a uma reação ao que considera a "falência" e "esterilidade" da modernidade (Nandy 2006:59). Como não poderia deixar de acontecer, isso tem sérias repercussões em suas obras. ${ }^{6}$

A civilização indiana - que exibe continuidade com seus vizinhos, apresentando-se, portanto, como maior que o Estado e a "nação" — seria especialmente acomodatícia e flexível, capaz de fazer empréstimos a qualquer um e viver com ambiguidades sem perder de fato sua identidade em 
função, em particular, de seu pluralismo civilizacional interno (que seria de fato capaz de absorver tudo com a "lenta, soporífica capacidade sedativa do hinduísmo diuturno", tão temida pelo islamismo no subcontinente, por exemplo). Nesse tipo de concepção de mundo, oposições binárias são recusadas. O próprio termo "hindu" foi cunhado pelos muçulmanos para referirem-se aos indianos que não se haviam convertido ao Islã, e somente no século XIX se tornaria uma categoria autoaplicada, sem que a sobreposição entre religião e nacionalidade fosse importante para essa autoidentificação (Nandy 2000b:76-9; 1988:103-4, 111, nota 84; 1990c:49; 1995d). ${ }^{7}$

\section{As vicissitudes do self}

Esse universo civilizacional indiano começa a se fazer mais claro quando exploramos sua concepção de nacionalismo e patriotismo, a partir do pensamento de Gandhi e Tagore, na verdade seus dois grandes ídolos intelectuais. Aproximamo-nos assim do núcleo central, a meu ver o mais produtivo, da obra de Nandy.

A história do colonialismo inglês e a luta pela independência da Índia são evidentemente os grandes temas do século XIX e da primeira metade do XX no sul da Ásia. O nacionalismo emergiu então com enorme força. Gandhi e Tagore mantiveram, contudo, uma relação no mínimo ambivalente com esse tipo de ideologia, quando não abertamente hostil, pois ela configuraria uma perspectiva particularista e atrasada. Tampouco o universalismo abstrato serviria como alternativa, alternativa esta que seria de fato um universalismo "enraizado na tolerância codificada em várias formas tradicionais de vida em uma sociedade altamente diversa e plural" (Nandy 1994:vi-viii). Gandhi e Tagore, com ênfases distintas e por vezes amargas disputas públicas, não obstante a estima e respeito mútuos, compartilhavam essa visão, aquele tentando lidar com as divisões entre ocidente e oriente, passado e presente, moderno e tradicional, com referência à cultura de "baixo", este se orientando pelo nível da "alta" cultura. Jawaharlal Nehru (1889-1964), seguidor de ambos e o principal político prático do período, percebeu que seria uma combinação das duas estratégias o que poderia legitimar o nascente Estado indiano. Gandhi e Tagore temiam o nacionalismo e não queriam que a ideia de uma nação indiana suplantasse a de civilização indiana. Assim, optaram pelo patriotismo contra o nacionalismo (Nandy 1994:1-3).

Além disso, Tagore era contra métodos violentos que vinculavam a cultura do oprimido à cultura do opressor, quer utilizassem ou não a linguagem do Gita, livro sagrado da cultura védica, para justificar tal comportamento. 
A hipermasculinidade lhe era alheia, ameaçando a "autenticidade do eu feminino", crucial para a civilização indiana, como se vê em seus vários romances (Nandy 1994:26-42). Na verdade, a brutal violência do século XX foi um tema candente na agenda intelectual de Tagore de modo geral, recolhida diretamente por Nandy (2002f). No caso de Gandhi isso é ainda mais óbvio no que se refere especificamente à Índia, o que atraiu o ódio dos nacionalistas radicais. Ele sempre buscou uma identidade andrógina, típica de uma visão de santidade no subcontinente, em que o princípio feminino era superior, com destaque para a temática da maternidade amplamente concebida, embora pensasse que a masculinidade era melhor que a covardia. Mobilizou para isso a cultura indiana e os elementos recessivos do cristianismo, que acreditava serem compatíveis com os principais fatores do hinduísmo e do budismo, dentro de sua perspectiva decididamente universalista. Crítico de uma "normalidade" forçada, procurou preservar aspectos infantis em seu eu e afirmou a superioridade dos oprimidos, buscando, mediante a Satyagraha, uma resistência ativa e pacífica que desafiava a dureza violenta e masculina da cultura imperial inglesa, embora a violência fosse justificável em certas ocasiões. Gandhi abolia deste modo o elo entre ativismo, potência e agressão que se encontra no cerne da cultura ocidental, democratizando e publicizando, em contrapartida, o primeiro na própria sociedade indiana (Nandy 1990d:38; 1990d:74; 1992b:127-9, 143-4; 1988:4-55).

No entanto, Gandhi ao mesmo tempo aceitou um compromisso entre o nacionalismo que adentrava a Índia como uma categoria imperial e aquele que emergia das aspirações democráticas de sua população. Tinha esperanças de que o segundo superaria o primeiro, ao fim e ao cabo. Tagore, em compensação, praticou o anti-imperialismo rejeitando o nacionalismo, uma vez que a unidade da Índia era para ele um fato social antes de uma agenda política. Hoje, contudo, é o nacionalismo duro que prevalece: a visão de patriotismo de ambos praticamente desapareceu, o que para a maioria dos indianos, desgraçadamente, é motivo de orgulho e não de tristeza (Nandy 1994:77-83). Destaca-se com isso a visão do movimento Hindutva, com seu nacionalismo de direita e marcialidade - de resto, algo típico dos príncipes colaboracionistas com o Império britânico, bem como do terrorismo oposicionista, porém igualmente dependente daqueles poderes no plano mais profundo. Nesse tipo de nacionalismo são fundamentais a tentativa de organizar um Estado potente em moldes ocidentais e uma religião hindu "semitizada", com um "eu" rígido e delimitado, uma doutrina fechada, despluralizada, e uma organização hierárquica do clero. Nele se forjaria uma cultura masculinizada, agressiva, competitiva e calcada no princípio do desempenho, que proporcionaria a ressurreição das culturas marciais 
indianas e afastaria sua insegurança frente ao masculismo do colonizador que, entretanto, acabaria totalmente internalizado. O nacionalismo radical hindu rejeitava a dominação britânica ou islâmica, mas não o ocidente. É o que se vê no discurso e na política do assassino de Gandhi, Nathuram Godse (1910-1949), e de Vinayak Damodar Sawarkar (1883-1966), que abraçaram suas "defensas egoicas" mediante a identificação com o opressor — aliás, como ocorre amiúde com os judeus em Israel em relação a seu passado recente na Europa, pois nesse sentido se trata de fenômeno de alcance mais geral (Nandy 1990d; 1988:4-25; 2007a:147; 1987:35; 1994; 2003b:21; 2009a).

O imperialismo teve graves consequências também para os britânicos. Sua cultura endureceu e foi homogeneizada, congelando o intelecto e desencorajando a crítica, com o mecanismo do isolamento da cognição em relação ao afeto cumprindo papel fundamental. Tratou-se de uma "perversão da cultura ocidental" (Nandy 1988:4-6, 32-5, 48). É o que se expressa na análise que Nandy faz do grande escritor anglo-indiano Rudyard Kipling (1865-1936). Ele observa que em relação a Kipling amiúde se sugere uma bifurcação, com a ambiguidade de falar ele com uma voz dominante, marcial, violenta e moralista, e outra, subjugada, mais suave, feminina. Criado quase como um indiano, embora enviado à Grã-Bretanha na adolescência, onde enfrentou grandes dificuldades pessoais, seu problema era não poder ser indiano e ocidental ao mesmo tempo; a necessidade de fazer uma escolha gerou clara autodestrutividade, pois seus valores confessos eram ocidentais, mas seu "eu subsocializado e rejeitado" era indiano. Isso evidenciava a posição unilateral dos ingleses, visto o oriente lhes permanecer estranho, algo com que Kipling se punha em conflito, enquanto, para os indianos em geral, ser indiano e ocidental era um fato da vida cotidiana, com os temas culturais comuns, dominantes e recessivos, atravessando essas fronteiras (Nandy 1988:70-6). Fica claro aqui o imperativo moral de libertar também o opressor.

Isso nos transporta para as discussões mais conceituais de Nandy sobre o colonialismo e seus efeitos na Índia, bem como para sua teoria do self, intraduzível palavra em inglês que venho vertendo como "eu" ao longo deste texto. Para ele, o colonialismo é antes de tudo um estado de espírito, evidenciando uma colonização das mentes, processo do qual terminam sendo cúmplices os próprios indianos e colonizados em geral, até mesmo quando o enfrentam, fazendo-o, contudo, dentro dos "limites psicológicos" dados pela situação colonial e mediante a alteração de suas "prioridades culturais". Se esse colonialismo mental é produzido por fatores externos, tem um efeito de retroalimentação em relação a eles. Ele sobrevive — o que é pior - à queda dos impérios no espírito dos colonizados. ${ }^{8}$ Nesse sentido, 
a psicologia política pode desempenhar papel de destaque, demonstrando como isso se processa (Nandy 1988:x-xiv, 1-3). Por outro lado, Nandy crê que a subjetividade humana concretiza, melhor que nenhuma outra dimensão, o estado da política em uma sociedade - o "eu" absorve e expõe "telescopicamente" os conflitos sociais, inclusive, em um rápido flerte inconfesso com Georg Mead, o que chama de "outros significativos" (Nandy 1990g: viii; 2000b:41; 2002c:209).

Assim, ele tem duas razões, acredito, uma cognitiva, a outra programática, para investigar a construção do "eu" na Índia colonial e pós-colonial. Trata-se de partir daí e, indo além do valor intrínseco da análise, utilizá-la para compreender uma dinâmica social mais ampla - e seria mais quanto ao estudo de pessoas que de agregados que, por formação, se sentiria mais confortável. Entretanto, põe-se também a questão de defender um tipo particular de construção da subjetividade que caracterizaria a cultura indiana de forma bastante específica, pois no subcontinente o "eu" — seja individual, seja coletivo — não é bem definido ou claramente delimitado. Já o outro aparece "telescopicamente" no próprio "eu" como seu integrante, incluindo por outro lado partes de si mesmo - o que se espelha em uma multiplicidade do "eu" nas construções não dicotômicas dos conceitos de bem e de mal, bem como na capacidade de conviver com ambiguidades, o que, por exemplo, causava desconforto a Kipling (Nandy 1988:104; 2002e:107, 126-7; 2002b:148-9; 2006:55-7). Curiosamente, contudo, nessas passagens a psicologia profunda da psicanálise desponta modestamente, com apenas os mecanismos de defesa se apresentando de maneira mais forte em termos das explicações que Nandy oferece. Porém, em outros escritos, em sua maioria anteriores, este não é o caso. Vale notar que sua teoria da criatividade é bastante rica e tem cunho social, pois observa que não se trata de focalizar o mero jogo interno do desejo sexual ou testes rígidos de aptidão, mas sim de investigar como ela emerge a partir do encontro das necessidades individuais com os protótipos sociais que se oferecem ao cientista - e como ele resolve as tensões daí oriundas (Nandy 1995a:18).

Isso se evidencia em seus estudos sobre a ciência, especificamente a relativa a um conjunto de cientistas indianos que, na virada do século XIX para o XX, marcaram época. O primeiro é Jagadis Chandra Bose (1853-1937), físico e botânico, cuja mãe caracterizava-se por uma compulsão obsessiva com a limpeza - uma "angularidade tolerável" na cultura hindu — além de um comportamento misto de raiva e busca da perfeição, ambas posteriormente atravessando a postura de seu filho. A ocidentalização de Bose implicou uma aceitação da agressividade e competitividade, nele próprio latentes, o que o levou, pela mediação de sua esposa, figura feminina mais 
acolhedora, a superar as primeiras identificações, menos conflituosas, com seu pai, inclinado ao diletantismo. Foi então que pôde mergulhar em seu "eu mais profundo" e explorar a carreira científica de maneira decidida. Partindo de uma distinção entre brahman (essência) e atman (realidade essencial do eu) e da busca de absolutos atemporais via conhecimento empírico, Bose traduziu isso numa visão científica que, calcada no monismo hindu tradicional, mediado pelo bramohismo renovador semitizado, facilitava a integração de sua própria personalidade. A Índia podia, deste modo, também absorver qualquer coisa, integrando o vivo e o não vivo, vida agressiva ativa e morte pacífica, violência humana e natureza; assim, sua ciência tornou-se um "empreendimento reparador ou restitutivo", ao mesmo tempo articulando uma preocupação mais profunda com seu povo. Contudo, na verdade, cientificamente a pesquisa de Bose em biologia das plantas, com seu animismo monista, não lhe granjeou mais que curiosidade internacional, ao contrário de seu importante trabalho anterior, sobre eletricidade (Nandy 1995a:28-43, 62-71).

Srinavasa Ramanujan (1887-1920), um matemático brâmane de família pobre proveniente de uma vila de menor proporção, é o outro objeto principal de Nandy. Homem bastante feminino e com uma clara desordem compulsiva, aceitável na cultura indiana, ele era um autodidata genial que, entretanto, basicamente redescobriu as verdades da matemática de sua época, com dificuldades nas demonstrações técnicas. Psiquicamente afastava o afeto por meio da neutralização de emoções que uma ciência tão abstrata como a matemática permite (Nandy 1995a:88-143). Seu contato com a modernidade foi, contudo, mais tênue e menos ameaçador, pois não enfrentou os mesmos problemas que Bose, lidando com disciplinas que o ocidente dominava incontestavelmente. Ramanujan foi capaz de integrar sua matemática a sua filosofia metafísica e interpretações mágicas, vinculadas a sua mãe, ao passo que Bose terminou pressionado pela situação colonial e pelo nacionalismo, sem alcançar solução adequada nos termos da alta cultura de Bengala naquele momento. É revelador de sua atitude e perspectiva nessa altura que Nandy ache a derrota de Bose muito mais importante que a capacidade de autoisolamento de Ramanujan, uma vez que àquele se punha o problema contemporâneo de como integrar à cultura indiana novos elementos (ocidentais), almejando um conhecimento universal e forjando uma nova identidade na busca da "autonomia intelectual" da Índia (Nandy 1995a:143). De certo modo, este foi também o caso do primeiro psicanalista indiano, Girindrasekhar Bose (1886-1953), que mistura a psicanálise com teorias indianas mais antigas acerca da subjetividade. Ele teria cultivado, sem se expor totalmente a Freud e seus colegas europeus da época, um "eu 
secreto", mais especulativo, em oposição a uma psicanálise mais positivista, criticando tanto a cultura indiana tradicional quanto a imitação da cultural ocidental pelas classes médias (Nandy 1995b). ${ }^{9}$

Se na ciência ele parece vislumbrar essa questão que, de maneira até certo ponto positiva, se punha para a Índia, aos poucos fica claro que sua visão tem outro ângulo, mais duro e agudo. Este acabaria por terminar abafando essa abordagem original, mais transigente com o ocidente e a modernidade.

\section{Estado, nacionalismo e desenvolvimento, secularismo e secularização}

Nandy foi treinado como psicólogo e psicanalista, com conhecimento razoável de outras áreas associadas à teoria social e política, mas é no manejo destas disciplinas que, embora por vezes tenha boas intuições e seja capaz de situar amplamente alguns processos cruciais mais gerais, ele tende a se perder. É quando vemos sua crítica à modernidade fazer-se mais estridente, com pouca compreensão de fato de seus processos, o que termina por toldarlhe a visão. Obviamente, para isso contribui um programa político e cultural cada vez mais distante, em princípio, da modernidade, hostil a ela, calcado por sua vez em um voluntarismo para o qual as escolhas sociais não apenas são fundamentalmente morais, como também se constituem em terreno de ampla liberdade para os sujeitos.

Nandy (2009a) está perfeitamente ciente de que às mudanças de identidade na Índia, sob o impacto da modernidade e da modernização, subjazem processos que tiveram a ver com o colonialismo, mas que mais amplamente se referem à urbanização e à industrialização. O Hindutva, assim como o islamismo indiano e o budismo no Sri Lanka - parte da mesma configuração civilizacional indiana, que abarca o Paquistão e a ilha no sudeste do subcontinente, com conflitos entre sinhaleses e tâmiles - passa por transformações racionalizadoras que demonizam o outro, como forma de "exorcismo" de seus eus recusados, mesmo que à custa do autoaniquilamento - a proximidade, e não a distância, sendo responsável por essa mobilização emocional, como no "narcisismo das pequenas diferenças" que Freud denunciara, conquanto ele não o cite nesse contexto. A ideia de uma Índia com continuidade cultural e rigidez tem apelo exatamente para pessoas desenraizadas, que vivem uma cultura de fluxo e uma busca de segurança e constância no plano psíquico (Nandy 2003h; 2007c:38). Anteriormente, seguindo um diagnóstico comum à esquerda indiana e à teoria de Adorno sobre a personalidade autoritária, Nandy (1990e) identificava esses proces- 
sos com o fascismo. Por outro lado, o fanatismo religioso derivava da raiva flutuante e do ódio a si mesmas gerados nas pessoas que se viam derrotadas religiosamente em um mundo crescentemente secular e dessacralizado, criado pela modernidade (Nandy 2002e:74).

Isso fica claro em particular em sua discussão sobre o sati, suicídio ritual das viúvas. Tratava-se de uma "patologia" da cultura indiana desde sempre, que sofreu uma perversão com o avanço da modernidade, que atacou e desorganizou estilos de vida tradicionais e entregou a religião, inclusive essa prática específica, além de festivais e romarias, aos mecanismos de mercado (Nandy 1995e). Já no século XVIII ocorrera uma "epidemia" de sati, forçada por transformações sociais e culturais na vida dos babus (castas brâmanes) de Calcutá. O recurso maciço ao sati surgiu como uma tentativa de demonstrar conformismo a uma tradição ameaçada e por desencadearem-se fantasias e medos masculinos de agressão por parte das mulheres, com a suposição de que a morte estaria sobrevindo em virtude de seu parco desempenho ritual - o que poderia ser contornado em parte mediante a realização do suicídio ritual feminino (Nandy 1990a). Vale notar que o raciocínio, embora preciso ao apontar mecanismos, desloca a responsabilidade da resposta para as causas oriundas da modernização, com certa tendência a desonerar moralmente os que então recorreram — ou fizeram as mulheres de Bengala recorrer - ao sati. O voluntarismo às vezes lhe serve como argumento, em outras ocasiões é descartado.

Por outro lado, ainda que por vezes reconheça que das classes médias provêm críticas tanto à tradição quanto à modernidade (Nandy 1995c:197), são elas as acusadas ao abordar a questão do dezenraizamento, do vilipêndio das tradições populares e do radicalismo intolerante do nacionalismo hindu, pois é daí que emergiria fundamentalmente o que há de negativo na Índia contemporânea (Nandy 2008b). Independentemente da correção ou não do aspecto sociológico que subjaz a essas afirmações, fato é que somos assim transplantados de chofre ao plano da moralidade e das escolhas voluntárias, contudo, agora com sinal negativo, ao contrário do que se passava com a discussão sobre a "epidemia" do sati. O Estado e o secularismo evidenciam ainda mais esta apreciação negativa do papel das classes médias, em oposição à maioria da população indiana. O secularismo teria sido introduzido no país por gente "seduzida ou que sofrera lavagem cerebral" em favor das teses etnocidas da evolução social e da história de modo a subverter as formas tradicionais de tolerância religiosa. E seriam exatamente as classes médias que apostariam naquele Estado-nação de fato etnofóbico e etnocida, exceto se as culturas se curvarem a ele (Nandy 2002a:64; 2003i:68). Exploremos em mais detalhes estas teses explosivas, que se mostram estreitamente entrelaçadas. 
Nandy não tem qualquer simpatia pelo Estado, embora esteja mais ou menos confortável com um de tipo mais "moderado", encolhido e capaz de lidar com uma "federação" de culturas. O Estado-nação, sonho dos nacionalistas indianos, seria mero produto do colonialismo, seu fruto mais problemático, começando na mente em grande medida, embora a maioria das pessoas na Índia se vinculasse a ele no cotidiano, o que, de resto, remete a uma antiga tradição subcontinental de alheamento ante o Estado. Este, aliás, não tem legitimidade - a que tinha derivava da que lhe conferiu a geração da independência. Hoje o que teria legitimidade seria a democracia, que se expande apesar de muitos problemas e do poder crescente do aparelho estatal. Altera-se, por outro lado, o modo de "acomodação" que prevaleceu até recentemente no país, cultivado por Nehru, pelos comunistas em Kerala e Bengala ocidental, bem como por outras lideranças, uma vez que o Estado vem sendo obrigado a lidar com uma sociedade não moderna no fim das contas. Em contrapartida, as "culturas" já não aceitam imposições passivamente (Nandy 2002d:36, 51; 2002a:69; 2002e:104-5; 2003a: xii; 2003a:8-12; 2003b:21, 29; 2003h:111; 2003i:77; 2006:128). Mesmo os movimentos nacionalistas radicais, derrotados nas eleições de 2009, talvez tenham aprendido algo precisamente sobre esssa tendência à acomodação tão típica da Índia, não obstante as fortes inclinações à esquerda do eleitorado, em que uma radical diversidade, ao contrário da tolerância aguada, por exemplo, à política estadunidense, gera um cosmopolitismo não domesticado (Nandy 2009b).

O desenvolvimento seria outra desgraça que se abate sobre o país e se encontra estreitamente associado a esse Estado cada vez mais forte e que, na visão de Nandy, a meu ver equivocada, oscila entre certa solução de continuidade com o Estado nehruviano e sua mera extensão, o que não faz sentido. ${ }^{10}$ Muito simplesmente, esse legado do colonialismo e de sua "missão civilizadora" funciona por oposições binárias — com sinal trocado, observe-se, em relação às propostas pelo próprio Nandy hoje... - em que se opõe antes de tudo ao subdesenvolvimento, mas cujas duplicações incluem as oposições entre "sanidade" (normalidade) e "insanidade" (anormalidade), "maturidade" (fase adulta) e "imaturidade" (infância), além de "racionalidade" e "irracionalidade", tudo disposto sem tempo suficiente para se discutir o tema. Trata-se, pois, de simplesmente abandonar a questão do desenvolvimento, buscando alternativas enraizadas na cultura indiana - quando a questão das formas tradicionais de gestão do meio ambiente se apresenta como possibilidade a ser explorada (Nandy 2003e; 2003a; 2003c).

Chegamos, enfim, ao tema explosivo dos conflitos comunais, que na Índia e em todo o subcontinente querem dizer, sobretudo, conflitos reli- 
giosos, cujo caráter étnico, observe-se de passagem, é bastante discutível. Segundo Nandy, o secularismo - que só pode medrar como ideologia em sociedades não secularizadas - teria dois significados na Índia: primeiro, o da desvalorização da religião e a libertação de sua política, fundamentalmente a visão anglo-saxônica; em segundo lugar, o de ser igualmente respeitoso ou desrespeitoso em relação a todas as religiões - uso não moderno, que a elite "anticolonial indiana" enfatizou e fazia sentido para a população. Seria de se esperar que ele voltasse a discutir sobretudo esta questão. Todavia, para surpresa do leitor, ele decide deixá-la de lado, por óbvias razões estratégico-discursivas, pois assim é mais fácil propor sua alternativa como a única viável. Ele segue então realçando a diferenciação entre religião como "ideologia" e religião como "fé", na qual busca as "capacidades em termos de tolerância étnica" contra a religião na condição de ideologia e as ameaças a ela vinculadas que emergem da Índia modernizante, que incluem um Estado voltado para a engenharia social neste terreno (Nandy 2003d:34-5, 47-53, 59; 2003i:62, 71). No entanto, seu raciocínio se faz mais amorfo ao afirmar que o secularismo é apenas uma maneira de garantir a tolerância religiosa, tendo se convertido, contudo, em um contraponto ao chauvinismo religioso, competindo com ele (Nandy 2003i:77). Como vimos, ademais, a modernidade hoje nada de bom teria a oferecer, a não ser deslocamentos sociais que contribuem para o fortalecimento da religião como ideologia. Ele já afirmara, entretanto sem argumentos sólidos, que os conflitos comunais são rebentos malignos da modernidade exclusivamente, embora tenham constituído problemas de menor monta em épocas anteriores (Nandy 1992b:154)

Ele voltaria ao tema atribuindo mais uma vez dois significados ao secularismo, como acomodação ou expulsão da religião da vida pública. Além disso, reafirma uma oposição entre religião como ideologia — ampla, monolítica e utilizada com objetivos não religiosos, mas sim políticos e econômicos, além de pública, mas pouco relevante privadamente - e religião como forma de vida - de cunho transcendente e capaz de tolerância - conquanto admitindo que não sejam formas mutuamente excludentes. Ele se chamaria de antissecularista porque essa ideologia teria exaurido suas potencialidades e a ideia de secularismo como tolerância, adotada originalmente por Gandhi, teria sido recusada pelos intelectuais como uma adulteração, ainda que até recentemente os políticos recorressem a ela preferencialmente. De qualquer modo, com a democratização a religião teria readentrado a cena política pela porta dos fundos (Nandy 2002a:61-74). Se a exclusiva modernidade dos conflitos comunais é bastante discutível, mas plausível, ainda que unilateral e inclinada a eximir os setores populares de responsabilidade efetiva 
por distúrbios e massacres, a violência é organizada em grande medida de cima para baixo, servindo a interesses políticos específicos. Assim, Nandy (2002e:82-3) admite, com Kakar, que defesa do ego, submissão autoritária e sadomasoquismo, deslocamento e racionalização ainda provêm de uma demonologia que opera na divisão entre comunidades e autoriza a violência religiosa. Entretanto, argumenta que se tornaram menos centrais, pois atuam sobre os que participam das agitações, não sobre os que de fato as planejam, iniciam e legitimam, os quais exibem defesas mais primitivas, como o isolamento e a denegação. ${ }^{11}$

Não se trata de recusar liminarmente as teses de Nandy nesse sentido, embora ele as apresente de forma tal que acabam por se mostrar bastante implausíveis, jogando tudo na conta da expansão da modernidade, como se a história da Índia demonstrasse uma convivência benigna desde sempre entre religiões (e etnicidades...) que a modernidade envenenou mutuamente. Ainda que isto fosse verdade, que remédios oferecer é questão que não pode ser decidida simplesmente recorrendo-se à desqualificação das alternativas modernas. Mais sofisticação é requerida também do conceito de secularismo, cujo duplo, secularização, como processo, não como ideologia, não chega a figurar nas discussões de Nandy, em particular nos interstícios da sociedade indiana. Isso, porém, não deve implicar que a temática em si proposta por Nandy seja irrelevante: não há razão para desconsiderar as possibilidades que, contra um dogmatismo que cancela o convívio respeitoso e o debate reflexivo, podem ser localizadas em formas tanto populares quanto racionalizadas da religião no mundo moderno, no qual a Índia se encontra inarredavelmente envolvida, como Nandy mesmo é repetidamente obrigado a reconhecer, ainda que com malgrado. Sem dúvida, pode haver tensões entre um processo de secularização (como perda de importância da religião) e o secularismo como visão de mundo, de um lado, e a busca de tolerância dentro das próprias religiões. Nada disso implica necessariamente, como querem alguns dos mencionados na introdução, que haja uma aliança entre as forças do Hindutva e "antissecularistas" como Nandy. Provavelmente uma reafirmação de um Estado transigente, junto ao combate a formas duras e exclusivistas de nacionalismo religioso, será a resposta que prevalecerá nos próximos anos se houver de fato um encaminhamento positivo dessas questões, quaisquer que venham a ser, a longo prazo, os vetores preponderantes de maneira geral na sociedade indiana. Com certeza o antimodernismo nesse sentido é mais uma ideologia que uma prática vivida, pois é na confluência desses múltilpos elementos civilizatórios, em um processo de acelerada modernização, que a Índia encontra seus caminhos concretos no tempo presente. ${ }^{12}$ 


\section{Conclusão}

Tratamos ao longo deste texto de variados temas e concepções apresentadas por Nandy. Isso nos permitiu não apenas conhecer com certo detalhamento sua obra, mas também delinear algumas das tradições em que se baseia o que se poderia classificar como uma civilização índica, tema controverso evidentemente, obviamente sem que devamos aceitar uma definição essencialista dessa entidade fundamentalmente histórica. Por outro lado, ainda que Nandy recuse cada vez mais violentamente a modernidade, parece bastante evidente que é com ela que tem de manter seu diálogo. Em que medida poderia expulsá-la, por assim dizer, de uma renovada civilização indiana? "Em nenhuma medida" seria a minha resposta e em muitos momentos a do próprio Nandy. Ademais, embora não valha a pena sublinhar este ponto, pois suas ideias devem ser julgadas por si mesmas, é relevante observar que isto pode dizer respeito ao próprio "eu secreto" de Nandy, cuja família é de origem cristã, sendo ele mesmo muito ocidentalizado em vários aspectos (Paranjape 2000:244-6), sem se converter por isso em uma figura "inautêntica".

Consideremos, para concluir, dois aspectos da questão, um derivado de sua própria obra, o outro externo, mas diretamente relacionado a suas reflexões. Em seguida, retornaremos à questão do self de um ponto de vista mais genérico.

Ao discutir o críquete e sua enorme e surpreendente popularidade na Índia, Nandy sugere, com seu humor peculiar, que este seria "[...] um jogo indiano acidentalmente descoberto pelos ingleses". O críquete poderia ser visto como a dominância de uma mentalidade colonial, porém igualmente como uma importação que contemplava uma "necessidade vital da cultura indiana" em sua tentativa de lidar com a modernidade e emprestar-lhe sentido em termos de "categorias nativas", além do "puramente endógeno (indigenous)", embora por vezes localize o críquete na tradição pré-moderna (Nandy 2001:1-2). Deixemos de lado sua detalhada análise em que os aspectos de maior esportividade e mera expressão lúdica contrapõem-se à competitividade, cujo predomínio vem se fazendo absoluto, e concentremo-nos na pergunta acerca de em que medida uma importação ocidental, moderna, pode ser considerada absolutamente "autêntica", para fazer uso do termo do próprio Nandy. Se este fosse o caso com o críquete, ${ }^{13}$ como ele próprio assinala, abrir-se-ia um enorme espaço para que a mesma questão se pusesse em qualquer esfera e em relação a qualquer elemento civilizacional com essa origem e que penetrasse o subcontinente sul-asiático. Mesmo as formas mais radicais de abandono da tradição hindu na região ou semelhantes se legitimam, uma vez que se trata daquilo que é socialmente requerido 
e em parte livremente eleito por aqueles que adotam esse tipo de inovação importada. Esse seria o caso hoje, pode-se argumentar, de muitos Dalits (os intocáveis em vocabulário tradicional). Isso parece a Nandy (2007a:149) incompreensível, pois essas castas teriam uma cultura que vai muito além da opressão sofrida, o que para elas parece importar menos do que garantir uma ruptura com os sistemas de dominação e discriminação a que têm sido subordinados. Dada a situação, ele se espanta, critica esses sujeitos, mas não chega a recriminá-los.

Aqui vale realizar uma pequena digressão, derivada de argumentos propostos por Nigam (2000), com clara, ainda que apenas implícita, inspiração em Nandy (Nigam é hoje pesquisador do CSDS). Segundo o autor, a política dos Dalits se confronta com oposições binárias, atravessando-as, especialmente em relação aos temas do nacionalismo-colonialismo e secularismo-comunalismo. Se não tem simpatias indigenistas e é decididamente moderna, rejeita por outro lado o universalismo abstrato da cidadania moderna, implicando uma epistemologia alternativa e sendo parte de uma reação dos "pequenos eus" contra o "Homem Universal". Essa alternativa não pode ser abarcada pelo nacionalismo homogenizador nem pelo marxismo e seu reducionismo classista, ambos abstratamente universalistas. Os Dalits enfatizam tanto a emancipação moderna, a linguagem dos direitos e a secularização do espaço público quanto elementos particularistas na política, pois seu eu tem de ser, necessariamente, construído contra o "Outro brâmane". Ambedkar, a grande liderança Dalit da luta pela independência e um dos pais da Constituição indiana de 1949, oscilava entre universalismo e particularismo, ao passo que outras lideranças optaram pela rejeição por ser excessivamente universalista.

Não deixa de ser curioso que Nandy jamais tenha discutido uma figura tão imponente como Brimhao Ramji Ambedkar (1891-1956), mas não é disso que trato aqui. Cabe, sim, assinalar o quanto na verdade tudo que é moderno, como o críquete, termina assimilado, na Índia bem como em outras áreas não ocidentais e originalmente afastadas da modernidade, devido às demandas dos próprios eus individuais e das coletividades, mais ou menos organizados e mutuamente identificados desta forma, ou seja, em função das disputas culturais, políticas e econômicas que atravessam essas formações sociais. Nandy percebe esses processos com certas oscilações em muitos momentos de sua obra e em particular na supracitada análise do esporte de nascimento britânico. Esquece-os, contudo, com demasiada e crescente frequência. Vale notar ainda que se uma crítica externa - em certa medida no que tange à origem de seus elementos civilizatórios — pode ser localizada em países não ocidentais a sua modernização dá lugar a "giros modernizadores" 
(Domingues 2009) que eles mesmos trazem, como vemos no posicionamento Dalit face ao universalismo abstrato, uma crítica já imanente, conquanto não necessariamente ocidental, à modernidade.

Quanto à questão do self de um ponto de vista teórico mais geral, é interessante observar que as proposições de Nandy nos oferecem pontos de partida importantes, que podem ser ademais conjugados aos de Castoriadis (1975; Domingues 1999), com sua noção de "imaginário radical" (localizado no "isso" ou "id" individual — o Es freudiano) e de um magma social mais ou menos amorfo, que se constrói como um depósito vivo de significações flutuantes. Os "eus", com seus núcleos criativos que derivam da força do desejo, da pulsão de vida e de como os conflitos internos dos sujeitos são organizados, podem ser vistos, certamente, como múltiplos, vinculados a esse magma, no qual buscam significações que eles próprios transformam ao organizar sua identidade de forma mais ou menos estável. Nos processos interativos entre indivíduos e coletividades, essas significações transformadas são devolvidas à sociedade em um processo permanente de desenvolvimento das subjetividades e do universo simbólico social, o próprio magma. Se o que Castoriadis chama de "apoio" somático da subjetividade no corpo não deve ser esquecido ou posto de lado, posto que altera significativamente a noção mais simples de Freud sobre a sexualidade e a vida subjetiva e a social, a ideia de que o desejo é mediado pela forma como o sujeito organiza seus conflitos e os da sociedade em seu próprio eu, como sugere Nandy, permite que levemos a discussão a um patamar superior, na articulação entre corpo, psique e sociedade. Isso é aplicável à Índia e também a qualquer formação social que tenha emergido ao longo da história da humanidade, cada uma evidentemente apresentando características distintas: no caso ocidental, um modo mais rígido e fechado, no indiano, mais aberto e fluido.

Em suas virtudes, intuições e amplitude, bem como em seus limites e idiossincrasias, a obra de Nandy pode nos auxiliar muito quanto à compreensão da sociedade indiana e ao avanço na teoria social, sem alinhamentos acríticos, sem sua estridência antimoderna, mas decerto também sem uma rejeição que descarte seus aspectos criativos e positivos, a partir dos quais podemos pensar a crescentemente reconhecida heterogeneidade da civilização moderna em sua fase atual e em suas coordenadas cada vez mais explicitamente globais. 
José Maurício Domingues é pesquisador do IUPERJ e da UERJ. E-mail: <jmdomingues@iuperj.br >

\section{Notas}

${ }^{1}$ Informações biográficas encontram-se em Nandy 2000b. Na medida do possível, as citações de seus textos incluem a data original de publicação - nem sempre explícita em suas coletâneas, mesmo porque os escritos têm com frequência diversas encarnações.

${ }^{2}$ Suas discussões sobre o sati - suicídio ritual cometido pela esposa quando da morte do cônjuge, discutido em seguida - estão na origem desse tipo de acusação, a meu ver pouco fundada, embora sua crítica sarcástica às "feministas ocidentalizadas", como de hábito, obscureça mais que esclareça a questão (ver Nandy 1990a; 1990d; 1995e). Segundo Nandy, toda discussão sobre reforma social na Índia, bem como discursos conservadores, incluem a questão da mulher como tema chave na política cultural. Todavia, para não ficar confinada a pequenos grupos ocidentalizados, a emancipação da mulher deveria ter como eixo imediato a mudança da relação diádica entre mãe e filho, típica dessa civilização, para a conjugalidade, redefinindo-se assim em primeiro lugar o papel da mulher. Uma importante elaboração psicanalítica destas questões, centrada na sexualidade e que se debruça inclusive sobre o próprio Gandhi, nesse sentido curiosamente negligenciado por Nandy, se encontra em Kakar 1989.

${ }^{3}$ Em português, até onde sei, apenas Peirano (1988) menciona os trabalhos (mais antigos) de Nandy.

${ }^{4}$ Algo vinculado a seu ceticismo quanto à narrativa histórica e à história como conceito (Nandy 1987:121-2), transformado em crescente hostilidade e em um favorecimento, bastante pouco convincente, de uma narrativa baseada em mitos (Nandy 1988:xiv; 2003h; 2007g). Isso articula ainda a sua crítica ao Estado-nação e à ciência.

${ }^{5}$ Vale notar que, instado por um entrevistador, Vinay Lal, Nandy (2000b:44-7) não conseguiu definir de modo algum o que seria a "autenticidade", observando em outra passagem que, quando o ocidente imita, o chamam de "cosmopolita", ao passo que quando outros o fazem são chamados de "inautênticos (Nandy 2006:115). Óbvia imprecisão e, além disso, ambiguidade evidenciam-se nessas passagens.

${ }^{6}$ Vanaik (1997:130-ss) prefere apontar um "espaço cultural" aberto, multidimensional, pois não se poderia falar de uma civilização hindu ao longo dos séculos e em área tão vasta. Para uma discussão detalhada do conceito de civilização na teoria social 
contemporânea e uma proposta alternativa que destaca a fluidez e a pluralidade das civilizações, bem como sua unidade provisória e histórica, ver Domingues 2009.

${ }^{7}$ Note-se que, embora por vezes a ênfase na religião e na espiritualidade perpasse os textos de Nandy, ele afirma até mesmo que a Índia não diz respeito principalmente a espiritualismo, mas sim a escolhas mundanas, autointeresse duro e "teste da realidade" (Nandy 1988:81).

${ }^{8}$ Como observa em outras passagens, a ideia de desenvolvimento e a ciência, bem como noções de secularismo - em suma, a cultura em geral - criam um "colonialismo interno" (que não explica nem descreve). Ele se transplanta então a outros planos societários, como o de um "colonialismo interno" econômico (ver Nandy 2002a:85-6; 2003b:27).

${ }^{9}$ Rammohun Roy (1772-1833) e Sri Aurobindo (1872-195) são outros personagens cruciais para o debate intelectual e as reformas sociais na Índia sob domínio britânico, assim como para a luta pela descolonização, analisados por Nandy e que não investigaremos aqui. Discutir a passagem das vilas e seus imaginários para o mundo urbano foi outra maneira pela qual Nandy (2007d) interpretou as transformações do self na Índia ao longo do século XX.

${ }^{10}$ Ver Kaviraj (2005) para a discussão sobre a tradição estatal indiana, começando com os antigos estados hindus, seguidos pelos mugais - que, embora islâmicos, vieram de uma região na Pérsia em que eram minoria - e para sua (demasiado rápida, é verdade) observação de que entre o Estado construído no período pós-independência e o atual há muitas diferenças. No fundo Nandy sabe disso, embora insista polemicamente acerca da continuidade, que desmente em várias passagens, sobretudo em textos mais antigos, e bem claramente em sua análise do período de Indira Gandhi (Nandy 1990f ).

${ }^{11}$ Todos esses temas ressurgem em sua narrativa e análise, junto a outros autores, da destruição da secular mesquita em Ayodia por nacionalistas hindus, ponto de virada na política indiana no começo dos anos 1990 (ver Nandy, Trivedy, Mayaran, Yanik 1997).

${ }^{12}$ A questão do secularismo envolve um tenso e complexo debate. Ver Veer, 1994; Vanaik, 1997; Madan, 1997 e 2006. Chatterjee (1998 [1994]), por exemplo, busca uma alternativa ao secularismo, cuja capacidade de garantir tolerância questiona, pois é apropriado com viés exclusivista pela direita nacionalista. Ao contrário de Nandy, porém, quer enfrentar o problema dentro das instituições estatais modernas. Autonomia ante a governamentalidade estatal, com tolerância e direitos coletivos, atinentes a grupos outrossim internamente democratizados, é a solução por ele proposta, a qual mantém, todavia, um caráter principal e excessivamente normativo.

${ }^{13}$ Appadurai (1996) é ainda mais incisivo quanto ao caráter moderno do críquete e sua importância para a organização simbólica da modernidade na Índia. 


\section{Referências bibliográficas}

APPADURAI, Arjun. 1996. "Playing with modernity: the decolonization of Indian cricket". In: Modernity at large. Cultural dimensions of globalization. Minneapolis: University of Minnesota Press. pp. 89-113.

BABER, Zaheer. 2006. Secularism, communalism and the intellectuals. Gurgaon: Three Essays.

BUELL, Frederick. 2000. "Ashis Nandy and globalist discourse". In: Vinay Lal (org.), Dissenting knowledges, open futures. The multiple selves and strange destinations of Ashis Nandy. Nova Déli: Oxford University Press. pp. 309-333.

CHAKRABARTY, Dipesh. 2000. "The modern Indian intellectual and the problems of the past: an engagement with the thoughts of Ashis Nandy". In: Vinay Lal (org.), Dissenting knowledges, open futures. The multiple selves and strange destinations of Ashis Nandy. Nova Déli: Oxford University Press. pp. 249-259.

CASTORIADIS, Cornelius. 1975. L'institucion imaginaire de la société. Paris: Seuil.

CHATTERJEE, Partha. 1998. "Secularism and toleration". In: A possible India. Essays in political criticism. Nova Déli: Oxford University Press.

CHATTERJI, Angana. 2009. Violent gods. Hindu nationalism in India's present. Narratives from Orissa. Gurgaon: Three Essays.

DESAI, Radhika. 2002. Slouching towards Ayodhia. Nova Déli: Three Essays Press.

DIRLIK, Arif. 2000. "Reading Ashis Nandy: the return of the past; or modernity with a vengeance". In: Vinay Lal (org.), Dissenting knowledges, open futures.
The multiple selves and strange destinations of Ashis Nandy. Nova Déli: Oxford University Press. pp. 260-286. DOMINGUES, José Maurício. 1999. Criatividade social, subjetividade coletiva e a modernidade brasileira contemporânea. Rio de Janeiro: Contra Capa. - 2002. Interpretando a modernidade. Imaginário e instituições. Rio de Janeiro: Editora FGV.

. 2009. "Modernity and modernizing moves: Latin America in comparative perspective". Theory, Culture \& Society, XXVI(7-8):208-227.

GREEDHARRY, Mrinalin. 2008. Postcolonial theories and psychoanalysis. Houndmills: Palgrave.

KAKAR, Sudhir. 1989. Intimate relations. Exploring Indian sexuality. Nova Déli e Harmondsworth: Penguin.

KAVIRAJ, Sudipta. 2005. "On the enchantment of the state: Indian thought on the role of the state in the narrative of modernity". Archives Europeéns de Sociologie, XLVI(2):263-296.

LAL, Vinay. 2000. "The defiance and liberation for the victims of history: Ashis Nandy in conversation with Vinay Lal". In: Vinay Lal (org.), Dissenting knowledges, open futures. The multiple selves and strange destinations of Ashis Nandy. Nova Déli: Oxford University Press. pp. 3-96. . 2001. "Subaltern studies and its critics". History and Theory, XL.

MADAN, T. N. 1997. Modern myths, locked minds. Nova Déli: Oxford University Press. . 2006. Images of the world. Essays on religion, secularism, and culture. Nova Déli: Oxford University Press.

NAG, Dulali. 2002. "A post-colonial end to history? A reflection on the relation 
between democracy and communitarianism". Contributions to Indian Sociology, XXXVI(3):525-549.

NANDA, Meera. 2004. Prophets facing backwards. Postmodernism, science, and Hindu nationalism. Déli: Permanent Black.

NANDY, Ashis. 1987. "Cultural frames for social transformation: a credo". Alternatives, XII(1):113-123. - 1988 [1983]. The intimate enemy. Loss and recovery of the self under colonialism. Nova Déli: Oxford University Press.

- 1990a [1980]. "Sati: a nineteenth century tale of women, violence and protest". In: At the edge of psychology. Essays in politics and culture. Nova Déli: Oxford University Press. · 1990b [1976]. "Woman versus womanliness in India. An essay in cultural and political psychology". In: At the edge of psychology. Essays in politics and culture. Nova Déli: Oxford University Press.

- 1990c [1980]. "The making and unmaking of political cultures in India". In: At the edge of psychology. Essays in politics and culture. Nova Déli: Oxford University Press.

. 1990d. [1980] "Final encounter. The politics of assassination of Gandhi". In: At the edge of psychology. Essays in politics and culture. Nova Déli: Oxford University Press.

- 1990e [1980]. "Adorno in India. Revisiting the psychology of fascism in India". In: At the edge of psychology. Essays in politics and culture. Nova Déli: Oxford University Press. . 1990f [1980]. "Indira Gandhi and the culture of Indian politics". In: At the edge of psychology. Essays in politics and culture. Nova Déli: Oxford University Press.

. 1990g [1980]. "Preface". In: At the edge of psychology. Essays in politics and culture. Nova Déli: Oxford University Press.

. 1992a [1981]. "Science, authoritarianism and culture: on the scope and limits of isolation outside the clinic". In: Traditions, tyranny, and utopias. Essays in the politics of awareness. Nova Déli: Oxford University Press. . 1992b [1981]. "From outside the Imperium: Gandhi's cultural critique of the West". In: Traditions, tyranny, and utopias. Essays in the politics of awareness. Nova Déli: Oxford University Press.

. 1992c [1978]. "Towards a Third World utopia". In: Traditions, tyranny, and utopias. Essays in the politics of awareness. Nova Déli: Oxford University Press.

- 1992d [1984]. "Evaluating utopias: considerations for a dialogue of cultures and faiths". In: Traditions, tyranny, and utopias. Essays in the politics of awareness. Nova Déli: Oxford University Press.

. 1992e [1987]. "Preface". In: Traditions, tyranny, and utopias. Essays in the politics of awareness. Nova Déli: Oxford University Press. -1994. The illegitimacy of nationalism. Rabindranath Tagore and the politics of self. Nova Déli: Oxford University Press.

. 1995a [1980]. Alternative sciences. Creativity and authenticity in two Indian scientists. Nova Déli: Oxford University Press.

. 1995b [1990]. "The savage Freud: the first non-western psychoanalyst and the politics of secret selves in colonial India". In: The savage Freud and other essays on possible and retrievable selves. Nova Déli: Oxford University Press. . 1995c [1990]. "An intelligent critic's guide to Indian cinema". In: The savage Freud and other essays on 
possible and retrievable selves. Nova Déli: Oxford University Press. . 1995d [1992]. "The other within: the strange case of Radhabinod Pal's judgment of culpability". In: The savage Freud and other essays on possible and retrievable selves. Nova Déli: Oxford University Press.

. 1995e [1994]. "Sati in Kali Yuga: the public debate on Roop Kanwar's death". In: The savage Freud and other essays on possible and retrievable selves. Nova Déli: Oxford University Press.

. 1995f. "Preface". In: The savage

Freud and other essays on possible and retrievable selves. Nova Déli: Oxford University Press.

- 1995g [1990]. "The discreet charms of Indian terrorism". In: The savage Freud and other essays on possible and retrievable selves. Nova Déli: Oxford University Press.

. 2000a [1989]. "The after-life of the Raj in Indian academe". In: Vinay Lal (org.), Dissenting knowledges, open futures. The multiple selves and strange destinations of Ashis Nandy. Nova Déli: Oxford University Press. . 2000b. "The defiance and liberation for the victims of history: Ashis Nandy in conversation with Vinay Lal". In: Vinay Lal (org.), Dissenting knowledges, open futures. The multiple selves and strange destinations of Ashis Nandy. Nova Déli: Oxford University Press. pp. 3-96.

2001 [1989]. The Tao of cricket. On games of destiny and the destiny of games. Nova Déli: Oxford University Press.

.2002a [1990]. "The politics of secularism and the recovery of religious tolerance". In: Times warps. Silent and evasive pasts in Indian politics and religion. New Brunswick: Rutgers University Press. 2002b [1997]. "A report on the present state of health of the Gods and Goddesses in South Asia". In: Times warps. Silent and evasive pasts in Indian politics and religion. New Brunswick: Rutgers University Press.

. 2002c [2000]. "Time travel to a possible self. Searching for the alternative cosmopolitanism of Cochin". In: Times warps. Silent and evasive pasts in Indian politics and religion. New Brunswick: Rutgers University Press. - 2002d. "Democratic culture and images of the state. India's unending ambivalence". In: Times warps. Silent and evasive pasts in Indian politics and religion. New Brunswick: Rutgers University Press.

. 2002e. "Coping with the politics of faith and cultures. Between secular state and ecumenical traditions in India". In: Times warps. Silent and evasive pasts in Indian politics and religion. New Brunswick: Rutgers University Press.

. 2002f. "Violence and creativity in the late twentieth century. Rabindranath Tagore and the problem of testimony". In: Times warps. Silent and evasive pasts in Indian politics and religion. New Brunswick: Rutgers University Press.

. 2003a. "Preface". In: The romance of the State and the fate of dissent in the Tropics. Nova Déli: Oxford University Press.

. 2003b. "Culture, state and the rediscovery of Indian politics". In: The romance of the State and the fate of dissent in the Tropics. Nova Déli: Oxford University Press.

- 2003c. "The scope and limits of dissent: India's first modern environmentalist and his critique of the DVC". In: The romance of the State and the fate of dissent in the Tropics. Nova Déli: Oxford University Press. 
2003d [1985]. "An anti-secularist manifesto". In: The romance of the State and the fate of dissent in the Tropics. Nova Déli: Oxford University Press.

. 2003e [1991]. "Culture, voice and development: a primer for the unsuspecting". In: The romance of the State and the fate of dissent in the Tropics. Nova Déli: Oxford University Press. - 2003f [1992]. "The State: the fate of a concept". In: The romance of the State and the fate of dissent in the Tropics. Nova Déli: Oxford University Press. . 2003g [1996]. "Development and violence". In: The romance of the State and the fate of dissent in the Tropics. Nova Déli: Oxford University Press.

. 2003h [1997]. "State, history and exile in South Asian politics: modernity and the landscape of clandestine and incommunicable selves". In: The romance of the State and the fate of dissent in the Tropics. Nova Déli: Oxford University Press.

. 2003i [1997]. "The twilight of certitudes: secularism, Hindu nationalism and other masks of deculturation". In: The romance of the State and the fate of dissent in the Tropics. Nova Déli: Oxford University Press.

- 2006. Talking India: Ashis Nandy in conversation with Ramin Jahanbegloo. Nova Déli: Oxford University Press. . 2007a [1983]. "Towards an alternative politics of psychology". In: Time treks. The uncertain future of old and new despotisms. Calcutá: Seagull. - 2007b [1989]. "Shamans, savages, and the wilderness. On the audibility of dissent and the future of civilizations". In: Time treks. The uncertain future of old and new despotisms. Calcutá: Seagull.

. 2007c [1997]. "The fantastic IndiaPakistan battle. Or, the future of the past in South Asia". In: Time treks. The uncertain future of old and new despotisms. Calcutá: Seagull. - 2007d [2001]. An ambiguous journey to the city. The village and other odd ruins in the Indian imagination. Nova Déli: Oxford University Press.

. 2007e [2002]. "Telling the story of communal conflicts in South Asia". In: Time treks. The uncertain future of old and new despotisms. Calcutá: Seagull.

. 2007f. "Humiliation. The politics and cultural psychology of the limits of human degradation". In: Time treks. The uncertain future of old and new despotisms. Calcutá: Seagull.

2007g. "Preface and acknowledgments". In: Time treks. The uncertain future of old and new despotisms. Calcutá: Seagull.

2008a. "Gandhi and Indian identity". In: R. Jahanbegloo (org.), India revisited. Conversations on contemporary India. Nova Deli: Oxford University Press.

. 2008b. "Blame the middle class". In $\mid$ : The times of India. Editorial 8 de janeiro.

. 2009a. "The demonic and the seductive in religious nationalism: Vinayak Damodar Savarkar and the rites of exorcism in secularizing South Asia". Heidelberg Papers in South Asian and Comparative Politics, 44.

. 2009b. "The hour of the untamed cosmopolitan". Tehelka, VI(32).

;; TRIVEDY, Shikha; MAYARAN, Shail; YAGNIK, Achyut. 1997 [1995]. Creating a nationality. The Ramjanmabhumi Movement and the fear of self. Nova Déli: Oxford University Press.

NIGAM, Aditya. 2000. "Secularism, modernity, nation: an epistemology of the Dalit critique". Economic and Political Review, XXXV(48). 
PARANJAPE, Makrand. 2000. "In the interstices of tradition and modernity: exploring Ashis Nandy's clandestine and incommunicable selves". In: Vinay Lal (org.), Dissenting knowledges, open futures. The multiple selves and strange destinations of Ashis Nandy. Nova Déli: Oxford University Press. pp. 233-248.

PEIRANO, Mariza. 1988. “'Are you a Catholic?' Relato de viagem, reflexões teóricas \& perplexidades éticas". Dados, XXXI(2):219-241.

SARDAR, Ziauddin. 2000. "The A B C D (and E) of Ashis Nandy". In: Vinay Lal (org.), Dissenting knowledges, open futures. The multiple selves and strange destinations of Ashis Nandy. Nova Déli: Oxford University Press. pp. 211-232.

VEER, Peter van der. 1994. Religious nationalism. Hindus and muslims in India. Berkeley e Los Angeles: University of California Press.

VANAIK, Achin. 1997. The furies of Indian communalism. Religion, modernity and secularization. Londres: Verso. 


\section{Resumo}

Este texto trata da obra de Ashis Nandy, um dos principais intelectuais indianos contemporâneos, psicólogo social, psicanalista, bem como cientista político, que busca desenvolver o que chamou de "tradicionalismo crítico". Sua discussão da personalidade e do indivíduo, dentro de uma concepção ampla da civilização da Índia, com a modernidade fazendo-se presente como ameaça explícita (e elemento implícito, mais ambiguamente), é crucial em vários sentidos - em particular teoricamente - para o entendimento da Índia e para uma teoria da civilização. A composição múltipla do self e suas relações tanto com a cultura índica quanto com a ocidental se destacam em sua discussão.

Palavras-chave Ashis Nandy, Índia, Civilização, Cultura

\section{Abstract}

This paper examines the work of Ashis Nandy, one of Indian's foremost contemporary intellectuals, a social psychologist, psychoanalyst and political scientist, responsible for developing what he calls a 'critical traditionalism.' Adopting a broad conception of Indian civilization in which modernity poses an explicit threat (and, more ambiguously, an implicit element), Nandy's discussion of personality and the individual is crucial at various levels - in particular theoretical - to understanding India and developing a theory of civilization. One of the prominent features of his discussion is the multiple composition of the self and its relations to both Indian and Western civilizations.

Key words Ashis Nandy, India, Civilization, Culture 